medulla, and if given early in sea-sickness we find it cures the affection. A drop-dose of liquor atropize sulphatis, B.P., in a teaspoonful of water, should be given every hour till the physiological effect of the drug is produced. The sedative action of atropine on the medulla renders altered sensory impressions inoperative in producing sea-sickness. It should be given early in the affection, as when the more advanced or secondary stage is reached its effect is not so marked, though still beneficial. In some cases sugar is found in the urine, due probably to the irritation of the diabetic centre in the medulla. Four minim-doses of Fowler's solution thrice daily is the best treatment in such cases. When called in after the affection has lasted two or three days, the medical man generally finds the patient greatly depressed, with a furred tongue, bowels obstinately constipated, pulse quick and weak. The best treatment at this stage is to have the bowels well moved by enemata. The atropine should be given as above, and the patient's strength supported by drachm-doses of a mixture composed of equal parts of brandy and iced water. The dryness of the throat caused by the atropine will be best relieved by small quantities of ice or iced lemonade. Valentine's meat juice or cold beeftea, "a little and often," will sufficiently nourish the patient till more solid food is relished. Bromides, like atropine, have a sedative action on the brain, but, to prevent sea-sickness, must be given in sufficient quantities to produce bromisation. Now, as bromism is a very serious condition, and one liable to affect a patient's reason and general health most injuriously, the bromides should be used with great caution, and only when prescribed and their action watched by a medical man. A late New York physician published a book on seasickness for the general public in 1881, in which he recommends travellers to "purchase a pound" of the bromides of potassium or sodium, and to take as much as ninety grains a day before coming on board, and to keep up a bromised condition during the voyage. This is dangerous advice, and the public should be warned against adopting it. I have seen lamentable results follow such abuse of the bromides. One case was that of a clergyman, who had taken ninety grains daily two days before coming on board and two days afterwards. I was called to see him during the night of the fourth day. He was insane, unable to remember, subject to illusions, and incoherent in his talk. This condition lasted seven days. Two business men of New York also came under my care, suffering in a similar manner. Both were married men, and the bromisation rendered them impotent for some months, and also incapacitated them for business. In such cases of bromine poisoning. I find nourish ing food, with small quantities of brandv and sal volatile, at regular intervals, the best treatment. Chloral hydrate is a useful drug in some cases of sea-sickness; its curative action seems to depend on its rendering the brain anæmic, as we find that the vaso-motor centre in the medulla is affected in the same way after loss of blood and under chloral. ${ }^{2}$

\section{ERACTURE OF THREE RIBS FROM MUSCULAR ACTION.}

By T. EDGAR UNDERHILL, M.B., F.R.C.S. EDIN., SURGEON TO THE GUEST HOSPITAL, DUDLEY.

W. B-, aged fifty-four, a strong and very muscular man, was engaged on April, 12th, 1884, in demolishing a brickkiln by means of a sledge-hammer which weighed a little over eight pounds. Ho was working in a narrow part with only just enough room to give his hammer its full swing, when suddenly he missed his stroke from the hammer catching against the side of the kiln, and was twisted violently round, cansing intense pain in the left side of his chest. On examination, a few hours afterwards, there were no marks of external violence, but there was unmistakable fracture of the sixth, seventh, and eighth ribs on the left side, a little in front of the angles; the man himself complaining of a sensation like "two rough bricks rubbing together." He is confident that the injury was caused by indirect violence, and not from being struck with the handle of the hammer or from falling against the side of the kiln.

Cases of fracture of the ribs from muscular action are comparatively rare, and according to Malgaigne never occur except where there is / some atrophic thinning or other

$$
2 \text { Ib'd, p } 162 .
$$

morbid change. In the present instance there is no evidence of preternatural brittleness in any bone ; on the contrary, although at different times in his life he has met with serious accidents, he has never had a bone broken. In his own district he is notorious for his strength and muscular development, and, although past middle life, has shown none of those atrophic and degenerative changes which generally accompany advancing age.

Tipton Green, Staffordshire.

\section{A tettirror}

\section{HOSPITAL PRACTICE, BRITISH AND FOREIGN.}

Nullaantem estalia pro certo noscendi via, nisi quamplurimas et morborum aliorum tum proprias collec inter se comparare.-Mosgagri De Sed. et Oaus. Morb., lib, iv. Procemium.

\section{HOSPITAL FOR CONSUMPTION, BROMPTON.}

ACUTE ABSCESS OF LIVER; NECROPSY; REMARKS.

(Under the care of Dr. KIDD)

Fon the report of the following case we are indebted to

Mr. H. Downes, M.R.C.S., resident clinical assistant.

Charles $\mathrm{H}-$, aged thirty-five, single, a labourer, was admitted an in-patient under Dr. Williams on Dec. 6th, 1883, but passed subsequently to Dr. Kidd's care. He first applied at the hospital as an out-patient, under Dr. Bruce, with chronic bronchitis, but coming up one day with high temperature and other serious symptoms, was sent into the wards. The patient had never been out of England. In 1881 he had diarrhoea with blood in stools, for five weeks, at Nottingham. He had had winter cough for years. Last October he caught cold, and had a severe cough, with considerable expectoration. For three weeks before admission he had attended as out-patient, and at first improved, but afterwards got much worse again. He had profuse expectoration, loose bowels, with slight nocturnal delirium, but no pain.

Un admission, the condition was as follows:-Complains of persistent cough, with profuse watery aerated sputum; restless, muttering to himself, but. rational ; skin dry, hot, and pungent; no icterus ; temperature $103.8^{\circ}$; pulse 124 , full and bounding; respiration 28, noisy; expiration prolonged; alæ nasi working; rbonchal fremitus over both fronts ; right base up to angle of scapula absolutely dull; vocal fremitus absent; breath-sounds weak; muffled sibilant râles ; loud, sonorous, and sibilant râles oyer the rest of the chest; tongue foul; bowels confined; appetite poor;' no nausea; no vomiting; abdomen tense and tympanitic; resonant to flanks; some epigastric tenderness; urine scanty, sp. gr. 1030, no albumen, but loaded with lithates. The tempera ture rose to $104.2^{\circ}$ the first two nights after admission; afterwards the daily average was from $100^{\circ}$ to $103^{\circ}$.

Dec. 13th: Slight icteric tint in the skin; right side cedematous over the lower ribs ; dulness over the lower ribs, increased upwards, most in the nipple-line, where it reaches the third rib, the fourth cavity of the sternum, and the middle of the scapula behind, continuing over the front of the abdomen, half way to the umbilicus from the edge of the ribs, where the edge of the liver can be felt. In the hypochondrium there is a firm, smootb, slightly tender mass; the abdomen is distended, and elsewhere tympanitic; no dulness in the flanks and no fluctuation. The heart's apex is in the sixth space, half an inch outside the left nippleline. The patient always lies on the right side, as any other position causes dyspncea. - 15th: The physical signs are the same; the patient's general condition is unchanged; two punctures were made with the hypodermic needle, one just below the angle of the scapula, and the other in the sixth space in front. Ooly a little dark blood was obtained.18th: Side more bulged; some tenderness in the light hypngastrium ; the physical eigns are the same as before A medium-sized aspirator-needle was inserted two inches below the ribs in the nipple-line, but no pus was obtained. 25 th : The patient complained of tightness across the chest; free from pain. - 26th: About 2 A.M. the patient began to congh severelv. and brought up some pus. Urgent dsspoce set 11 : pil.e 130, weak; reopiration 36. He remained in 